\title{
Belonging to CSHP-An Investment in Your Future and That of Hospital Pharmacy!
}

\author{
Glen J Pearson
}

An investment in knowledge pays the best interest. -Benjamin Franklin

W hat does it mean to be a part of our professional society, the Canadian Society of Hospital Pharmacists (CSHP)? Some members may not have considered this critical question for years, if ever. Others struggle with the issue annually at membership renewal time, contemplating how to justify the expense. So, do you consider your CSHP membership an expense or an investment? Perhaps it is both.

The term "expense" refers to the financial outlay associated with obtaining a product, service, or benefit. This straightforward transaction allows CSHP members to attend the Professional Practice Conference, read the Canadian Journal of Hospital Pharmacy, and access CSHP Official Publications. Many CSHP members place a high value on these and other products and services, and access to them is sufficient justification for the expense of membership. Other pharmacists, however, will lament the fact that they can access these things (directly or indirectly) without membership. So, membership in CSHP has to mean more.

I believe this is where hospital pharmacists need to carefully consider membership as an investment opportunity, an outlay with the expectation of future gains! Although many hospital pharmacists may never have considered the dividends they can expect from belonging to CSHP, this is where the true benefit of belonging to the Society lies.

CSHP supports members through advocacy, education, information-sharing, promotion of best practices, facilitation of research, and recognition of excellence. Development and growth of these CSHP efforts is where each member has the potential to gain substantially — in other words, where the future dividends arise.

Consider CSHP's substantial efforts in advocacy and health policy leadership. Although it may not be completely obvious to all hospital pharmacists, CSHP actively advocates for hospital pharmacists on numerous issues, such as prescribing, patient safety, and the promotion and support of interprofessional practice models. In addition, CSHP executive and staff members frequently respond to consultation requests from other organizations and the federal government on health policy; for example, we are members of a multistakeholder steering committee on drug shortages, provided input to the ProvincialTerritorial Expert Advisory Group on Physician-Assisted Dying, and prepared a

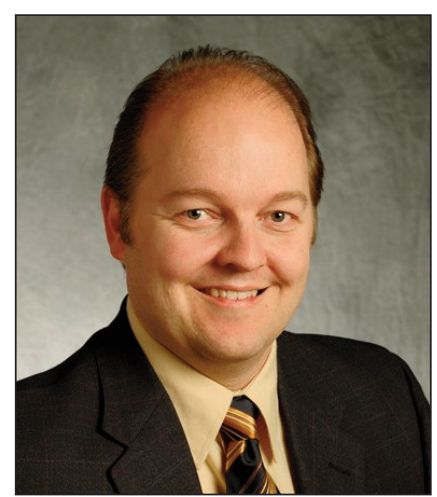
formal response to the federal External Panel on Options for a Legislative Response to Carter v. Canada. In addition, we confer regularly with various directorates of Health Canada on health and drug-related policies affecting hospital pharmacists, including drug shortages, drug recalls, provision of marijuana for medical purposes in hospitals, local destruction of narcotics and controlled drugs, and management of methadone prescribing to hospital inpatients. Although CSHP's efforts in these areas may, at first glance, seem far removed from the daily concerns of most hospital pharmacists, they arise directly from issues that affect, or could affect, hospital pharmacists' work. These important efforts are supported by your membership.

Your investment in the Society through membership is certainly an investment in the future of individual hospital pharmacy practitioners and the future of the profession. Consider these futures when you renew your membership, and encourage your hospital pharmacy colleagues to make a similar investment. Remember, "The achievements of an organization are the results of the combined effort of each individual" (Vince Lombardi). Get involved in the Society-your return on investment will increase markedly!

Glen J Pearson, BSc, BScPhm, PharmD, FCSHP, is President and External Liaison for the Canadian Society of Hospital Pharmacists. 